\title{
Conservação Preventiva: histórico ${ }^{1}$
}

Cleide Cristina Caldeira*

Para Abel, Bruno, Maria Helena, Rita e Otavio

\section{Resumo}

Este artigo identifica e reúne, de forma comparativa, os critérios adotados, ao longo do tempo, quanto à conservação preventiva de acervos documentais, buscando fomentar a conscientização em face de importância da conservação preventiva.

Palavras-chave: Conservação preventiva. Patrimônio cultural. Preservação.

\section{The Historic of Preventive Conservation}

This article identifies and reunites, in a comparative way, the criteria adopted over time about the preventive conservation of documents; it aims to promote the awareness towards the importance of the preventive conservation.

Key words: Preventive conservation. Cultural heritage. Preservation.

Os bens culturais ${ }^{2}$ são produtos concretos do homem, resultantes da sua capacidade de convivência com o meio ambiente, tais como objetos artísticos e/ou históricos, por exemplo: construções, obras plásticas, literárias e musicais.

Esses bens, como tal, testemunham materialmente a cultura humana e são importantes tanto para o conhecimento da história das civilizações como para os povos contemporâneos possam ver seus passado refletido nesses objetos e construir sua identidade. Por isso, a memória social depende da proteção dos elementos do passado e da forma pela qual estão ou podem se tornar ativos no presente. Nas palavras de FUNARI (2000, p. 30), em seu texto sobre os desafios da destruição e da conservação dos bens culturais, "não há identidade sem memória, como diz uma canção catalã: 'aqueles que perdem suas origens, perdem sua identidade também"'. 
Um estudo da história da humanidade nos mostra que desde tempos remotos existe preocupação em proteger os bens culturais da deterioração, conforme afirma ELIAS (2002 p. 16). Na Idade Antiga (que se inicia por volta do ano 3400 a.C. indo até o ano 476 d.C.) a civilização egípcia, por exemplo, visava manter o corpo físico de seus líderes (faraós) intactos, após a sua morte, por meio da mumificação, processo no qual o cadáver era submetido a um processo de embalsamamento com a utilização do sal como elemento preservativo. Também na Idade Antiga, há relatos, deixados em diferentes textos antigos, com referência à civilização romana, sobre a utilização de técnicas voltadas para a satisfatória manutenção física dos bens culturais desta civilização - como "o relato feito por Plínio sobre a limpeza realizada em Roma na obra Ato Trágico com Apolo, de Aristides, no ano 13 a.C." (ELIAS, 2002, p.16) que atesta a importância que Roma dava à longevidade de seus bens culturais.

Na Idade Média (476-1453), o elemento primordial de identidade cultural, na civilização ocidental, na Europa, foi encarnado pela Igreja Católica, que dominava toda a sociedade européia econômica, social e culturalmente. Desejando a manutenção do poder era interessante para a Igreja transmitir e perpetuar suas regras, inclusive por meio de suas bibliotecas e da longevidade física dos materiais nelas existentes.

Durante os séculos XVII e XVIII iniciaram-se pesquisas sobre causas da degradação. Nesse período, o pintor-restaurador Carlo Maratta dedicou-se a estudar meios para evitar problemas de deterioração em pinturas (ELIAS, 2002). No século XVIII, grandes descobertas arqueológicas aconteceram (como as de Herculano em 1738, de Pompéia em 1748 e de inúmeras tumbas egípcias). Em função dessas descobertas, diversas pilhagens ocorreram - principalmente por parte da Inglaterra, da França e da Alemanha. Com essas pilhagens várias coleções de museus foram acrescidas a diversos museus foram criados.

O primeiro museu a ser fundado, com o produto dessas pilhagens, foi o British Museum (1753), em Londres, para onde foram transportados todos os mármores do Parthenon, seguido pelo Museu do Prado (1787) em Madri e pelo Museu do Louvre (1793), em Paris, onde se encontram expostas várias esculturas que foram apropriadas indevidamente por Napoleão, durante a ocupação francesa em Roma (ELIAS, 2002, p. 20-21).

A criação desses museus universalizou o acesso aos bens culturais $\mathrm{e}$ institucionalizou as técnicas voltadas para a manutenção física desses bens. Em 
meados do século XVIII houve a imposição de leis pela Igreja e pelo Estado, no sentido de se proteger os bens culturais existentes.

Com a Revolução Francesa, ocorrida em 1789, sob o lema Igualdade, Liberdade, Fraternidade, a burguesia

tomou o poder na França, com apoio popular, e sustentou-se até 1815, quando se deu o fim do império napoleônico. Os revolucionários acabaram com os privilégios da nobreza e do clero e livraram-se das instituições feudais do Antigo Regime" (REVOLUÇÃO FRANCESA, 2003).

A partir deste momento ocorre a laicização do conceito de bem cultural. Esse, agora, se referia ao interesse público, implicando, até mesmo, uma limitação ao direito de propriedade em nome do coletivo (FUNARI, 2004). Com essa nova concepção inicia-se a noção de patrimônio público.

A Revolução Industrial, que começou na Inglaterra, em meados do século XVIII, e caracterizou-se pela passagem da manufatura à indústria mecânica, possibilitou a ascensão da burguesia às esferas de poder, produzindo mudanças políticas e econômicas que modificaram a atitude dos colecionadores de arte, resultando na entrada das classes menos favorecidas no mundo da cultura. Centrada no progresso científico e na introdução de novos materiais, a Revolução Industrial facilitou o enriquecimento cultural de todas as classes sociais e propagou princípios científicos e culturais graças a novas técnicas de impressão, aumentando o interesse das diferentes classes sociais pela educação. A ciência facultou ao povo a possibilidade de ver o mundo de uma outra forma: mais progressiva, racional e harmônica. Nessa fase surgiram novas ciências com campos de ação claramente definidos e com métodos próprios de trabalho (HERNAMPÉREZ, 2003). Entre essas novas ciências, nasceu - advinda do aprimoramento das técnicas da restauração a conservação de bens culturais e nela, embrionariamente, a conservação preventiva.

John Ruskin, na Inglaterra, foi um dos principais personagens para a construção do pensamento sobre conservação. Representante da teoria romântica, ou da restauração romântica, defendia a intocabilidade do monumento degradado. Era partidário da autenticidade histórica, acreditando que os monumentos medievais, representativos do antigo, deveriam ser mantidos sem modificação alguma. Tinha a destruição como uma idéia em si mesma bela, defendendo: 
a morte da edificação quando chegar o momento [e acreditando que] o ato de restaurar é tão impossível quanto o ato de ressuscitar os mortos.(...) Criado dentro de uma severa educação religiosa anglicana, ele parte do principio de que o homem, ao nascer, recebe em depósito bens que na realidade não Ihe pertencem, por isso deve fazer deles um uso respeitoso já que deverá prestar contas a quem o construiu e à humanidade vindoura (ELIAS, 2002, p.27).

Ruskin, indiretamente, deu os primeiros passos na direção da conservação preventiva, ao defender que as pedras de edifício ancestral deveriam ser tratadas como as jóias de uma coroa e que esse edifício sendo tratado com ternura e com respeito veria nascer e desaparecer à sombra de seus muros mais de uma geração (KOLLER, 1994), ao privilegiar a integridade e autenticidade física do bem e ao atentar para o fato de que a vigilância a um velho edifício, por meio dos melhores cuidados possíveis, o salvaria de qualquer causa de degradação.

Posteriormente, as concepções de Ruskin foram aprimoradas por Camillo Boito (1836-1914) que associou a teoria de John Ruskin à necessidade do restauro, prolongando a vida dos bens culturais por meio de várias técnicas (ELIAS, 2002). Após a Revolução industrial, a burguesia e o estado seguiram dirigindo o mercado cultural, acentuando o valor econômico dos objetos artísticos e codificando a cultura em termos de riqueza material. A manutenção física dos bens culturais consolidouse como meio de valorização de propriedades.

Com o advento da Primeira Guerra Mundial (1914-1918), novas correlações de forças estabeleceram-se no mundo. Devido aos estragos por ela provocados, tornaram-se necessárias maiores habilidades para tratar os bens culturais danificados. Assim, dentro das mudanças ocorridas na sociedade e na cultura após a Primeira Guerra Mundial os museus começaram a alcançar um notável grau de visibilidade como instituições públicas de ensino, pesquisa, programação cultural e formação social, ressaltando a importância das práticas adotadas para a adequada salvaguarda dos bens culturais.

A Segunda Guerra Mundial (1939-1945) fez mais vítimas, custou mais dinheiro, arrasou mais propriedades, afetou mais pessoas e, provavelmente, provocou maiores mudanças do que qualquer outra guerra ao longo da história (II GUERRA MUNDIAL, 2003).

Durante essa Guerra, o principio norteador adotado pelos invasores era: "tudo o que não puder ser removido seja destruído e queimado". A título de exemplo, 
menciona-se que os pelotões do ERR (Einsatzstab Reichsleitter Rosenberg) destruíram e roubaram várias bibliotecas judias (BATTLES, 2003).

Após a Segunda Guerra, ante a proporção das destruições provocadas pelo conflito bélico, a sociedade sensível e consciente de suas perdas culturais enfatizou a importância da cultura universal. A partir de então, uma dada obra produzida por um dado povo seria entendida não mais como pertencente apenas àquelas pessoas, mas sim pertencente à humanidade - já não existiam mais grandes realizações nacionais e sim grandes feitos da humanidade. Dessa forma, a proteção dos bens culturais passou a ser um direito e um dever de todas as sociedades as quais consolidam grandes instituições, como a ONU, encarregadas de assegurar a solução pacífica dos conflitos e defender os bens culturais.

Influenciada pela selvagem brutalidade do homem que provocou enormes perdas culturais, a população mundial conscientizou-se da importância da preservação do legado cultural. Houve na sociedade pós Segunda Guerra à tendência de acentuação da responsabilidade pela satisfatória sobrevivência dos bens culturais - considerando a segurança física desses bens em seu aspecto coletivo.

A partir do aprimoramento dos conceitos de restauro consolidaram-se os procedimentos advindos da responsabilidade social do mundo pós Segunda Guerra com referência à conservação preventiva. "Após a Segunda Guerra Mundial a comunidade de conservadores e restauradores era suficientemente numerosa para estabelecer suas próprias organizações” (ELIAS, 2002, p. 39). Segundo a mesma autora, foram criadas várias associações de classe internacionais, nacionais, regionais, municipais, de materiais específicos, tais como o International Institute for Conservation of Historic Objects and Works of Art (IIC), em 1950, e o United Kingdom Institute for Conservation (UKIC), em 1953.

Essas organizações estabeleceram diversos elementos regulamentadores da área de conservação/restauro e protetores dos bens culturais, levando em consideração Cartas de Restauro já existentes que contribuíram para a consolidação científica da Conservação Preventiva, concentrando sua ênfase "na importância de equilibrar a necessidade do uso, da compreensão e da apreciação do patrimônio cultural" (ELIAS, 2002, p.40). As Cartas que mais colaboraram para esta consolidação foram as seguintes: Carta de Atenas (1931), Carta de Veneza (1964) e a Carta da Itália (1987). 
A Carta de Atenas foi elaborada durante o I Congresso Internacional de Arquitetos e Técnicos em Monumentos (1931) e teve como temática a longevidade dos monumentos históricos, considerados como susceptíveis à ação ameaçadora dos agentes atmosféricos. Visando proteger os monumentos dessa ação degeneradora, a Carta recomenda que seja realizado o monitoramento constante das condições físicas dessas construções. Esse documento norteou os princípios gerais e as doutrinas relativas à proteção dos monumentos da restauração moderna (MARTINS, 1997). A Carta recomenda a adoção de diretrizes de caráter interdisciplinar - sugerindo a interação entre conservadores de monumentos, arquitetos, físicos, químicos - e a ampla divulgação dessas diretrizes (GURRIERI, 1992). Esse fato evidencia que a conservação preventiva começava, embrionariamente, a ser pensada de modo cientifico. Ela também salientou a importância do papel da educação quanto o respeito aos monumentos, solicitando que os educadores habituassem a infância e a juventude à não danificação dos mesmos, quaisquer que esses fossem.

A Carta de Veneza, por sua vez, foi elaborada no II Congresso Internacional de Arquitetos e Técnicos de Monumentos Históricos (1964) e contribuiu para o progresso da conservação preventiva ao incluí-la, ainda que indiretamente, nas diretrizes políticas do patrimônio cultural, reafirmando a relevância dos bens culturais e introduzindo a noção de conservação (ELIAS, 2002). Esse documento destaca os resultados obtidos pela Carta de Atenas de 1931, tais como: a publicação de vários documentos sobre preservação e conservação de monumentos e a criação, pela UNESCO, do Centro Internacional de Estudos para a Conservação e Restauração dos Bens Culturais (GURRIERI, 1992). Essa Carta reafirma o caráter científico da conservação preventiva, ao definir a conservação como sendo disciplina responsável pela salvaguarda do patrimônio monumental por meio da manutenção permanente e da associação das técnicas proveniente de várias ciências. Esse caráter cientifico também pode ser verificado no artigo $16^{\circ}$ dessa Carta, onde é mencionado que as atividades práticas desenvolvidas pela conservação serão sempre documentadas em relatórios analíticos e críticos, ilustrados com desenhos e fotografias e colocados à disposição dos pesquisadores nos órgãos públicos.

Em 1987, a Carta Italiana foi apresentada no Congresso Internacional sobre Bens Culturais e Ambientais. Ela consolida "Carta Italiana de Restauro" de 1972, apresentando definições afins à conservação preventiva, quais sejam: conservação, 
prevenção, salvaguarda, manutenção e restauração ${ }^{3}$. Ratifica a inter-relação existente entre esses conceitos, colocando que a conservação e restauração podem não acontecer unidas e simultâneas, mas são complementares e, de toda forma, um programa de restauração não pode prescindir de um adequado programa de salvaguarda, manutenção e prevenção.

Em seu Anexo $E$, oferece abordagens preventivas envolvendo livros. Consta nesse anexo a orientação para que, em casos de restauração, sejam evitadas todas as operações que possam alterar o aspeto e o valor global dos exemplares. Nesse sentido, aconselha que esses materiais sejam conservados o melhor possível, de modo que os seus elementos constitutivos sejam resguardados de danos e, conseqüentemente, a sua a funcionabilidade garantida. Indica que nas bibliotecas é oportuno, antes de tudo, realizar verificações periódicas sobre o estado de conservação dos acervos, efetuando nesses locais controles sistemáticos e prolongados dos valores termo-higrométricos ambientais com a finalidade de verificar se esses valores são mantidos, ao longo do ano, dentro dos limites ideais (quais sejam: temperatura, $16^{\circ}$ à $20^{\circ}$ e umidade relativa $40 \%$ à $\left.65 \%\right)^{4}$.

Coloca que os livros publicados do século XIX em diante são de pior qualidade que os precedentes, advindo daí a sua maior capacidade de deterioração. A última recomendação constante nesse documento dirige-se aos bibliotecários e conservadores em geral, orientando para que esses profissionais avaliem a urgência e a utilidade da restauração dos acervos, considerando, constante e atentamente a prevenção e manutenção dos mesmos (GURRIERI, 1992).

Em paralelo às Cartas de Restauro, Cesare Brandi (1906-1986), com seus cursos publicados como livro em 1963, contribuiu ao desenvolvimento da conservação preventiva "ao colaborar com o desaparecimento da reconstrução como tendência generalizada, tanto aos bens móveis quanto aos bens imóveis" (SILVA, 2002, p.164).

No Brasil, entre os esforços feitos para a conservação preventiva dos bens culturais destacam-se: o Compromisso de Brasília (abril de 1970) e o Compromisso de Salvador (outubro de 1971). O Compromisso de Brasília é o documento resultante do "Primeiro Encontro dos Governadores de Estado, Secretários Estaduais da Área Cultural, Prefeitos de Municípios Interessados, Presidentes e Representantes de Instituições Culturais". Esse encontro foi promovido pelo Ministério da Educação e Cultura, objetivando a adoção das medidas necessárias à 
defesa do patrimônio histórico e artístico nacional. Esse documento enfatiza que o acervo arquivístico e o acervo bibliográfico merecem cuidados especiais segundo as suas peculiaridades e conforme as regulamentações técnicas dos órgãos federais especializados na utilização e na proteção e desse patrimônio. Nesse sentido, destaca-se, entre as conclusões desse Encontro a orientação dada quanto à criação de cursos superiores - segundo orientações do Departamento Histórico Artístico Nacional (DPHAN) e do Arquivo Nacional - para a formação de arquitetos restauradores, conservadores de pintura, escultura e documentos, arquivologistas e museólogos. (INSTITUTO, 2004). Essa orientação ratifica, em nível nacional, a interdisciplinaridade da conservação preventiva e o seu caráter cientifico e a necessidade e importância de cursos superiores na área. A importância do documento gerado nesse Encontro está na sistematização da política de proteção aos bens naturais e de valor cultural (paisagens, parques, naturais, praias, acervos arqueológicos, conjuntos urbanos, monumentos arquitetônicos, bens móveis, documentos e livros).

O Compromisso de Salvador foi firmado no "Il Encontro de Governadores para Preservação do Patrimônio Histórico, Artístico, Arqueológico e Natural do Brasil", e subsidiado pelo Ministério da Educação e Cultura e pelo Instituto do Patrimônio Histórico e Artístico Nacional (INSTITUTO, 2004). Esse Compromisso ratifica o Compromisso de Brasília, ressaltando a necessidade de verbas especificamente direcionadas às atividades de manutenção física do patrimônio nacional, especialmente protegidos por lei. Além disso, ressalta a importância da criação do Ministério da Cultura e de Secretarias ou Fundações de Cultura nacionais e estaduais (INSTITUTO, 2004) Esse documento completa o primeiro, uma vez que aquele, elaborado em Brasília, propunha a formação de profissionais que atuassem junto à conservação do patrimônio nacional e esse propõem diretrizes, orçamentárias e legislativas, sem as quais a satisfatória manutenção do patrimônio nacional não acontece.

PAULA (1998), em sua dissertação de mestrado, discorreu sobre a noção de less is more que contribuiu para o enfraquecimento da utilização dos meios de reconstrução como tendência generalizada e ofereceu meios propulsores ao estabelecimento científico da Conservação Preventiva. A idéia de menos é mais, importada da Inglaterra, responsável pelo impulso inicial da Conservação Preventiva enquanto ciência foi sustentada pelos seguintes princípios fundamentais: fim do mito 
de reversibilidade de todo o tratamento, o princípio de máximo respeito e mínima intervenção e a necessidade de uma ética nos trabalhos. Esses princípios fundamentaram a necessidade da Conservação Preventiva e impulsionaram a origem de suas palavras-chave: prevenir, planejar, evitar.

A Conservação Preventiva surgiu, solidamente como campo de trabalho e pesquisa científica, nos Estados Unidos, na década de 80 estabelecendo-se como atividade responsável por todas as ações tomadas para retardar a deterioração e prevenir danos aos bens culturais por meio da provisão de adequadas condições ambientais e humanas. Assim, há cerca de 20 anos a Conservação Preventiva passou a ser pesquisada e, ao longo desse tempo, muito tem se trabalhado para o seu aprimoramento científico. Várias instituições internacionais direcionaram-se a esse fim disseminando e discutindo orientações com o objetivo de propiciar melhores condições de proteção aos bens culturais.

Atualmente, alguns autores consideram o controle ambiental como 0 principal enfoque de estudo das instituições voltadas para conservação preventiva dos bens culturais. MICHALSKI (2003) levanta que, em geral, as condições ambientais estão fundamentadas em valores ideais, pois o estabelecimento de valores absolutos é uma tarefa difícil. As áreas mais problemáticas se referem à umidade relativa e à iluminação. As especificações para os valores de UR, em ambientes com bens culturais, permaneceram inflexíveis durante os anos de 1960 e 1970.

Desde essa época, os parâmetros estabelecidos são de 50\%-55\% UR, aceitando-se como flutuações permitidas valores de, aproximadamente, $5 \%$ a mais ou a menos. Apesar de serem considerados como plausíveis, com o avanço cientifico da área observou-se que eram impossíveis de serem aplicados em situações reais. Por isso, esses parâmetros se converteram na recomendação de que sejam evitados extremos em temperatura e umidade e na indicação de que os níveis adotados sejam condizentes com história do objeto, sua constituição física e as possibilidades do local onde se encontram abrigados quanto ao fornecimento de infra-estrutura adequada para a sua sobrevivência em longo prazo. Sobre a iluminação, ainda pode-se considerar as recomendações feitas ao longo dos anos 30 como adequadas (entre 50 e 150 lux), pois oferecem equilíbrio entre uma boa visibilidade e a conservação dos bens. 
MICHALSKI (2003) informa ainda que a Conferência Internacional para Conservação Preventiva (IIC), ocorrida em Ottawa em setembro de 1994, ressaltou que é necessário despertar para a realidade. Nesse sentido, a medida mais importante para a conservação preventiva dos bens culturais é abordar a sua satisfatória manutenção física de forma especifica, de acordo com as possibilidades da instituição e a natureza e o estado de suas coleções.

Complementando as colocações feitas por MICHALSKI (2003), ressalta-se, como já vimos, que controle ambiental também inclui a temperatura - elemento esse que quase não foi citado - os valores ideais de temperatura e umidade relativa devem ser mantidos em $20^{\circ} \mathrm{C}$ e de $50 \%$, respectivamente. Por outro lado, enfatizase que muito mais problemático do que os extremos é a oscilação nos valores destes indicadores. É preferível uma temperatura constante de $30^{\circ} \mathrm{C}$ do que uma que varia entre $20^{\circ} \mathrm{C}$ e $25^{\circ} \mathrm{C}$ todos os dias.

Com referência à iluminação, deve-se considerar que os parâmetros indicados entre 50 e 150 lux não são válidos para os depósitos de livros e documentos raros - nesses locais, o parâmetro deve ser zero. Concordarmos com o autor no sentido de que medidas voltadas para a longevidade dos suportes informacionais devem ser adotadas de acordo com a situação física do suporte e com o contexto institucional no qual esse suporte está inserido.

\section{Notas}

${ }^{1}$ Este texto foi retirado da dissertação apresentada à Escola de Comunicações e Artes da Universidade de São Paulo, para obtenção do grau de Mestre em Ciências da Comunicação, sob orientação da Profa. Dra. Maria Helena Pires Martins (com banca composta pela Profa. Dra. Maria Christina Barbosa de Almeida e pela Profa. Dra. Heloisa Liberali Bellotto). A dissertação discutia a implementação de um Programa de Conservação Preventiva em bibliotecas públicas da cidade de São Paulo. Por meio dos dados coletados, foi possível sistematizar o grau de conhecimento técnico e os procedimentos empregados nestas bibliotecas para a conservação preventiva de seus suportes informacionais. Com isso, foi possível chegar, pelo consenso e dentro de condições reais, ao estabelecimento de parâmetros que auxiliem as bibliotecas públicas em geral na manutenção preventiva dos acervos bibliográficos.

\footnotetext{
${ }^{2}$ Esses bens são classificados como bens imóveis (núcleos urbanos, sítios arqueológicos e paisagísticos e bens individuais) e bens móveis (coleções arqueológicas e acervos museológicos, documentais, arquivísticos, bibliográficos, videográficos, fotográficos e cinematográficos), segundo Iphan (2004). Para fins desse artigo, as referências feitas aos bens culturais estarão direcionadas aos bens culturais móveis, especificamente os acervos bibliográficos.
} 
${ }^{3}$ Conservação: conjunto de atuações de prevenção e salvaguarda, direcionada a assegurar uma duração, que pretende ser ilimitada, para a configuração material do objeto considerado; Prevenção: conjunto de atuações de conservação, a mais longo prazo possivel, motivadas por conhecimentos prospectivos, sobre o objeto considerado e sobre as condições de seu contexto ambiental; Salvaguarda: qualquer medida de conservação e prevenção que não implique em intervenções diretas sobre o objeto considerado; Manutenção: conjunto de ações recorrentes nos programas de intervenção, encaminhadas a manter os objetos de interesse cultural em condições ótimas de integridade e funcionalidade, especialmente depois de que tenha sofrido intervenções excepcionais de conservação e/ou restauração; Restauração: qualquer intervenção que, respeitando os princípios da conservação e sobre a base de todo tipo de indagações cognoscitivas prévias, se dirija a restituir ao objeto, dentro do possível, uma relativa legibilidade e, onde seja necessário, o uso.

${ }^{4}$ Esses valores são indicados, nessa carta, como ótimos para a conservação dos livros.

\section{Referências Bibliográficas}

BATTLES, Matthew. A conturbada história das bibliotecas. Tradução: João Virgilio Gallerani Cutter. São Paulo: Planeta do Brasil, 2003.

CALDEIRA, Cleide Cristina. Conservação preventiva em bibliotecas públicas da cidade de São Paulo: estudo de campo. 2004. Dissertação (Mestrado) - Escola de Comunicações e Artes, Universidade de São Paulo, São Paulo.

ELIAS, Isis Baldini. Conservação e restauro de obras de arte em suporte de papel. 2002. 143 f. Dissertação (Mestrado) - Escola de Comunicações e Artes, Universidade de São Paulo, São Paulo.

FUNARI, Pedro Paulo A. Notas de leitura. Revista de História Regional, Campinas, v.4, n.1, p.147-149, 1999. [Análise dos livros: AUDRERIE, Dominique. La notion et la protection du patrimoine. Paris: Presses Universitaries de France, 1997. AUDRERIE, Dominique; SOUCHIER, Raphael; VILAR, Luc. Le patrimoine mondial. Paris: Presses Universitaries de France, 1998.] Disponível em: < http://www.rhr.uepg.br/v4n1/ funari.htm > Acesso em: 15 de janeiro de 2004.

Os desafios da destruição e conservação do patrimônio cultural no Brasil. Revista Adusp, São Paulo, v.19, p.30-33, 2000.

GURRIERI, Francesco. Restauro e conservazione: carte del restauro, norme, convenzioni e mozioni sul patrimonio architettonico ed artístico. Firenze: Polistampa Firenze, 1992.

HERNAMPÉREZ, Arsenio Sánchez. Paradigmas conceptuales en conservación. Disponível em <http://palimpsest.stanford.edu/byauth/hernampez/canarias.html> Acesso em 16 de abril de 2003.

INSTITUTO do Patrimônio Histórico e Artístico Nacional. Cartas patrimoniais. Disponível em <http://www.iphan.gov.br/legislac/cartaspatrimoniais/cartaspatrimoniais.htm> Pesquisado em 20 de maio de 2004.

KOLLER, Manfred. Learning from the history of preventive conservation. In: Coloque sur la conservation restauration des biens culturels, 1992, Paris. Anais... Paris. Association des restaurateurs d'art et d'archéologie de formation universitaire. 1992. p.1-7.

MARTINS, Maria Helena Pires. Políticas culturais de conservação de patrimônio: caso do mobiliário. 1997. 199 f. Tese (Livre-Docência) - Escola de Comunicações e Artes, Universidade de São Paulo, São Paulo.

MICHALSKI, Stefan. Directrices de humedad relativa y temperatura: que esta pasando? Apoyo: Associación para la Conservación del Patrimonio Cultural de las Américas, v.6, n.1, julho 1965. Disponível em: <http://apoyo.solinet.net/menuv61.htm> Acesso em 23 de novembro de 2003. 
PAULA, Teresa Cristina de. Inventando moda e costurando história: pensando a conservação de têxteis no Museu Paulista-USP. 1998. Dissertação (Mestrado) - Escola de Comunicações e Artes, Universidade de São Paulo, São Paulo.

REVOLUÇÃO FRANCESA. Disponível em <http://geocities.yahoo.com.br/vampire of death2000/revolucao franca .htm> Acesso em 23 de novembro de 2003.

II GUERRA MUNDIAL Disponível em <http://geocities.yahoo.com.br/vampire of death2000/guerra mundial2.htm> Acesso em 23 de novembro de 2003.

SILVA, Adriano Cruz Lara. Nacionalismo y reconstruccion: notas en torno al desarrollo delos criterios de restauración aplicados a objetos pré-hispánicos durante el siglo XX en México. In: Trienal Meeting, 13, 2002, Rio de Janeiro. Anais. Rio de Janeiro: ICOM-CC, 2002. p. 160-165.

*Bacharel em Biblioteconomia pela UNESP. Mestrado em Ciência da Informação pela USP. Bibliotecária da Seção de Obras Raras e Especiais da Biblioteca Mário de Andrade 